\title{
Sensitive and specific assay for the simultaneous detection of Mycoplasma genitalium and macrolide resistance-associated mutations
}

\author{
Joyce F. Braam ${ }^{1} \cdot$ Sebastian van Marm ${ }^{1} \cdot$ Tim T. Severs $^{1} \cdot$ Yevgeniy Belousov $^{2} \cdot$ Walt Mahoney $^{2} \cdot$ \\ Johannes G. Kusters ${ }^{1}$ (i)
}

Received: 16 June 2018 / Accepted: 8 August 2018 / Published online: 1 October 2018

(C) The Author(s) 2018

\begin{abstract}
Patients infected by Mycoplasma genitalium are often treated empirically with the macrolide azithromycin. Macrolide resistance is becoming quite common; empirical treatment is compromised. Sequencing was initially used to detected azithromycin resistance-associated mutations. As this was laborious, qPCRs have been developed for their detection. In the present study, we describe a fast, sensitive, and specific qPCR assay that enables routine testing of $M$. genitalium and macrolide resistanceassociated mutations in a single assay. M. genitalium positive clinical samples were used to compare (i) the commonly used $\mathrm{MgPa}$ assay for the detection of $M$. genitalium infections (MgPa qPCR), (ii) a combined 23S rRNA gene PCR/sequencing assay (Mg23S qPCR/Sequencing) to identify macrolide resistance-associated mutations, and (iii) our newly developed probe-based melt curve qPCR for simultaneous detection of M. genitalium and macrolide resistance-associated mutations (Macrolide-R/MG ELITe MGB Kit, Elitech Bothel USA in short Mg Macrolide ${ }^{\mathbf{R}}$ qPCR). Specificity of the qPCR was tested using urogenital samples that were tested positive for a range of other micro-organisms. M. genitalium was detected in 196/236 (83.1\%) samples by the MgPa qPCR, versus 172/236 (72.9\%) by the combined Mg23S qPCR/Sequencing, and 202/236 (85.6\%) by the Mg Macrolide $^{\mathbf{R}}$ qPCR. The Mg Macrolide ${ }^{\mathbf{R}}$ qPCR showed high concordance to the Mg23S qPCR/Sequencing assay (201 vs 202 could be genotyped, respectively) for the detection of the macrolide resistant mutations. None of the other urogenital pathogens were tested positive in the $\mathrm{Mg}$ Macrolide ${ }^{\mathbf{R}} \mathrm{qPCR}$, indicating specificity. The $\mathrm{Mg}$ Macrolide ${ }^{\mathbf{R}} \mathrm{qPCR}$ is fast, sensitive, specific, and can easily be implemented in the routine diagnostics.
\end{abstract}

Keywords Azithromycin resistance $\cdot \mathrm{qPCR} \cdot$ Mycoplasma genitalium $\cdot$ 23S rRNA $\cdot$ A2058T

\section{Introduction}

Mycoplasma genitalium causes sexually transmissible infections such as non-gonococcal urethritis (NGU) in man [1-3] and urethritis, pelvic inflammatory disease (PID), and cervicitis in women $[1,4,5]$. In addition, the bacterium is associated with extra-genital infections and an increased risk of obstetric complications such as premature birth and spontaneous abortion [5]. Furthermore, M. genitalium might also be associated with infertility in women [5]. $M$.

Johannes G. Kusters

h.kusters@umcutrecht.nl

1 Department of Medical Microbiology, University Medical Centre Utrecht, Heidelberglaan 100, 3584 CX Utrecht, The Netherlands

2 ELITechGroup Inc, Bothell, WA, USA genitalium infects between 1 and $3 \%$ of the people in the general population $[6,7]$.

Culturing $M$. genitalium is difficult since the bacterium is fastidious and requires special media and conditions [8]. Therefore, polymerase chain reaction (PCR) is mainly used for detection of $M$. genitalium. Diagnostic PCR tests for $M$. genitalium are mostly based on the target operon $\mathrm{MgPa}[9]$ and the 16S rRNA gene [10], but these methods are not suitable to determine the susceptibility of the bacterium to macrolides. Therefore, patients infected with $M$. genitalium are often treated empirically with a single-dose therapy of $1 \mathrm{~g}$ of the macrolide antibiotic azithromycin [11-13]. However, the Center for Disease Control and Prevention (CDC) and the European guidelines of the International Union against Sexually Transmitted Infections (IUSTI) of 2016 recommend to treat $M$. genitalium infections with $500 \mathrm{mg}$ azithromycin on day one, followed by $250 \mathrm{mg}$ on days $2-5$ [14]. 
Unfortunately, the meta-analysis of Lau et al. revealed that the efficacy of a single-dose of $1 \mathrm{~g}$ azithromycin for the treatment of urogenital M. genitalium has decreased from 85.3 to $60 \%$ over the past 7 years in the world [15]. This was mainly thought to be the result of an increase in azithromycin resistance, caused by mutations at positions A2058 and A2059 (Escherichia coli numbering) in region five (V-region) of the 23S rRNA gene. These mutations are associated with macrolide resistance of M. genitalium [16].

The macrolide resistance-associated substitutions (single nucleotide polymorphisms, SNPs) in the 23S rRNA gene are mainly identified by sequencing, which is a laborious and time-consuming technique. Recently, new tests are described to identify the substitutions in the 23S rRNA gene. Different methods are being used to identify these mutations, such as labeled hydrolysis probes [17], high-resolution melting (HRM) analysis [18-20], different forward primers targeting wild type and mutants [21], and FRET probes coupled with melting curve analysis [19]. However, these methods are less sensitive compared to the standard M. genitalium detection quantitative PCR (qPCR) or need more qPCR reactions to identify both $M$. genitalium and macrolide resistanceassociated genes. In addition, the analysis of some of the qPCRs is complex or the qPCRs are relatively laborious.

Alternatively, a new multiplex qPCR assay has been developed by SpeeDx that allows simultaneous detection of $M$. genitalium and mutations commonly associated with macrolide resistance (including A2058G, A2059G, A2058T, A2058C, and A2059C) [22, 23]. This multiplex qPCR has shown to be sensitive and specific for the detection of $M$. genitalium and macrolide resistance-associated mutations [24].

In the present study, a new qPCR that enables routine testing of M. genitalium and macrolide resistance-associated mutations in a single assay is described and its performance is compared to other molecular methods. The assay uses two probes: a hydrolysis probe for the specific detection of $M$. genitalium and a melt probe for the discrimination of mutants from wild types based on melting curve analysis [25].

\section{Materials and methods}

\section{Ethics statement}

Patients, and/or their legal representatives, visiting a Dutch hospital, are actively informed of the "opt-out" system regarding research on archival patient material. Dutch law requires all studies using such materials to obtain an official approval by the local ethics committee. The Medical Ethics Committee of the University Medical Centre Utrecht, The Netherlands (protocol number 16-238/C), has approved the current study. Only material from patients that did not opt-out has been included in this study.

\section{Sample selection}

Between January 2014 and January 2015, 236 urogenital samples were collected from Dutch patients that presented with urogenital symptoms in general practitioners or hospitals. The samples were sent in for routine molecular detection of $M$. genitalium. DNA was extracted essentially as described by Nijhuis et al. [26] and M. genitalium was detected in all 236 urogenital samples by qPCR essentially as described by Jensen et al. [27] and had been stored for more than a year at $-20{ }^{\circ} \mathrm{C}$. Collection was built to contain a good distribution of wild type and all potential resistance-associated mutations. In order to avoid patient bias, the collection did only contain a single sample of each patient. The origin of the samples can be found in Table 1.

\section{Routine qPCR detection of M. genitalium (MgPa qPCR)}

For this study, the M. genitalium positive DNA samples were tested for a second time to detect the $\mathrm{MgPa}$ operon and to determine the DNA load of M. genitalium. The DNA load had to be checked for DNA degradation, since the samples were stored for more than a year. qPCR was used for specific amplification of a 78-bp fragment in the $\mathrm{MgPa}$ operon of $M$. genitalium using primers and probe as described by Jensen et al. [27] (Table 2). DNA amplification and detection were performed using $2.0 \mu \mathrm{L}$ of DNA isolates and real-time PCR LightCycler ${ }^{\circledR} 480$ Software (Roche Diagnostics, Almere, the Netherlands). This $\mathrm{MgPa}$ assay is considered to be the standard method to detect M. genitalium and therefore used in the present study to compare with the newly designed $23 \mathrm{~S}$ PCR Macrolide-R/MG ELITe MGB Kit, Elitech Bothel USA, in short $\mathrm{Mg}$ Macrolide ${ }^{\mathbf{R}}$ assay.

\section{Identification of macrolide resistance-associated mutations by combined Mg23S qPCR and sequencing (Mg23S qPCR/sequencing)}

A 282-bp fragment of the V-region of the 23S rRNA gene was amplified essentially as described by Nijhuis et al. (2015) [26], but instead of a probe the dye Syto- 82 was used to detect $M$. genitalium (Table 2). The amplification product formed by the

Table 1 Summary of patient demographics and clinical samples used in Mg Macrolide ${ }^{\mathbf{R}}$ qPCR study

\begin{tabular}{llll}
\hline & Male & Female & Total \\
\hline Number & $80(34 \%)$ & $156(66 \%)$ & 236 \\
Median age (range) & $35(22-68)$ & $30(15-56)$ & $31(16-68)$ \\
Urine sample & 66 & 7 & 73 \\
Genital swab & 9 & 149 & 158 \\
Anorectal swab & 5 & 0 & 5 \\
\hline
\end{tabular}




\begin{tabular}{|c|c|c|c|c|c|c|}
\hline PCR & Target & Oligo name & Sequence $\left(5^{\prime}-3^{\prime}\right)$ & $\begin{array}{l}\text { Final concentration } \\
(\mathrm{nM})\end{array}$ & $\begin{array}{l}\text { Product } \\
\text { size }\end{array}$ & Source \\
\hline \multirow[t]{3}{*}{$\mathrm{MgPa}$} & \multirow[t]{3}{*}{$\mathrm{MgPa}$} & Mycgen-Fw & GAGAAATACCTTGATGGTCAGCAA & 300 & \multirow[t]{3}{*}{$78 \mathrm{bp}$} & \multirow[t]{3}{*}{ Jensen et al. [27] } \\
\hline & & Mycgen-Rev & $\begin{array}{l}\text { GTTAATATCATATAAAGCTCTACCGT } \\
\text { TGTTATC }\end{array}$ & 300 & & \\
\hline & & Mycgen-FAM & FAM-ACTTTGCAATCAGAAGGT-MGB & 200 & & \\
\hline \multirow[t]{4}{*}{$\mathrm{Mg} 23 \mathrm{~S}$} & \multirow[t]{4}{*}{$23 \mathrm{~S}$} & MG23S-Fw & GAAGGTTAAAGAAGGAGGTTAGCAAT & 150 & \multirow[t]{2}{*}{$282 \mathrm{bp}$} & \multirow[t]{2}{*}{$\begin{array}{l}\text { Nijhuis et al. } \\
\text { [26] }\end{array}$} \\
\hline & & MG23S-Rev & TACCTATTCTCTACATGGTGGTGTTT & 150 & & \\
\hline & & MG23S-RTN-Rw & AGGAGGTTAGCAATTTATTGCA & 150 & \multirow[t]{2}{*}{$263 \mathrm{bp}$} & \multirow[t]{2}{*}{ This study } \\
\hline & & MG23S-RTN-Rev & TCTCTACATGGTGGTGTTTTGA & 150 & & \\
\hline $\mathrm{Mg}$ & & MG23S-L1 & CTCGGTGAAATCCAGGTAC & 150 & $111 \mathrm{bp}$ & This study \\
\hline \multirow[t]{3}{*}{ Macrolide $^{\mathbf{R}}$} & & MG23S-E1 & TCTCTACATGGTGGTG2T*T*T*TGA & 1200 & & \\
\hline & & MG23S-FAM & G*GA*CGGAAA $*$ GACCCC & 167 & & \\
\hline & & MG23S-R6G & CGTTGCGCCTAACGGGTGTCTT & 167 & & \\
\hline
\end{tabular}

*Modification in the nucleotide for stronger bonding

standard Mg23S qPCR was used for Sanger DNA sequencing to identify possible macrolide resistance-associated mutations. Sequences were detected by an ABI 3730 System (Life Technologies).

The samples of which no sequences could be determined after the standard real-time Mg23S qPCR were then analyzed using a reverse transcriptase nested (RTN) - qPCR. An RTNqPCR can be used to increase the DNA load by first making cDNA of the rRNA followed by amplification and afterwards performing an extra nested-qPCR to increase the DNA load even more.

The RT-PCR was performed with $15.0 \mu \mathrm{L}$ final PCR volume using TaqMan ${ }^{\circledR}$ Fast Virus 1-Step Master Mix (Thermo Fisher Scientific) and the primers which had been used for the standard Mg23S qPCR (MG23S primers, Table 2). The mix contained $2.0 \mu \mathrm{L}$ of DNA isolates. The qPCR was performed on the LightCycler 480 II (Roche) using the following qPCR profile: reverse transcription at $50{ }^{\circ} \mathrm{C}$ for $5 \mathrm{~min}$, denaturation at $95^{\circ} \mathrm{C}$ for $2 \mathrm{~min}, 45$ amplification cycles consisting of $95^{\circ} \mathrm{C}$ for $5 \mathrm{~s}$, and annealing and extension at $62{ }^{\circ} \mathrm{C}$ for $1 \mathrm{~min}$. Directly after amplification, a melting step was performed, consisting of $95{ }^{\circ} \mathrm{C}$ for $5 \mathrm{~s}, 65^{\circ} \mathrm{C}$ for $1 \mathrm{~min}$, and a slow increase in temperature to $97{ }^{\circ} \mathrm{C}$ with the continuous acquisition of fluorescence and finally cooling at $40{ }^{\circ} \mathrm{C}$ for $30 \mathrm{~s}$.

Next, the nested-PCR is directly performed. 2.0- $\mu 1$ amplicon of the RT-PCR was used for 15.0- $\mu$ PCR mixture using LightCycler® 480 Probes Master (Roche Diagnostics) as master mix, the dye Syto-82, and the MG23S-RTN primers (Table 2). The following qPCR profile was used: denaturation at $95{ }^{\circ} \mathrm{C}$ for $10 \mathrm{~min}, 45$ amplification cycles consisting of $95{ }^{\circ} \mathrm{C}$ for $5 \mathrm{~s}$, annealing at $57{ }^{\circ} \mathrm{C}$ for $5 \mathrm{~s}$, and extension at $72{ }^{\circ} \mathrm{C}$ for $1 \mathrm{~min}$. Directly after amplification, a melting step was performed, consisting of $95{ }^{\circ} \mathrm{C}$ for $5 \mathrm{~s}, 65^{\circ} \mathrm{C}$ for $1 \mathrm{~min}$, and a slow increase in temperature to $97{ }^{\circ} \mathrm{C}$ with the continuous acquisition of fluorescence and finally cooling at $40{ }^{\circ} \mathrm{C}$ for $30 \mathrm{~s}$ to check if amplification product had been formed. Next, the amplification product of $263 \mathrm{bp}$ formed by the RTN-qPCR was used for Sanger DNA sequencing.

\section{Detection of macrolide resistance-associated mutations by the newly designed Mg Macrolide ${ }^{R}$ qPCR}

For the $\mathrm{Mg}$ Macrolide $^{\mathbf{R}}$ assay, species specific primers (MG23S-L1 and MG23S-E1) were designed (Table 2), according to the $23 \mathrm{~S}$ rRNA gene sequence after alignment of the $M$. genitalium gene with the genes of closely related species, such as M. pneumoniae, M. hominis, M. gallisepticum, and Ureaplasma parvum. The designed primers and probes (Table 2) were analyzed using a Basic Local Alignment Search Tool (BLAST, http://blast.ncbi.nlm.nih.gov/Blast.cgi) for their specificity. If $M$. genitalium is present, a 111-bp amplicon will be formed, and two probes are used in order to detect the specifics of this fragment: the MG23S-R6G probe, which is a hydrolysis probe, and MG23S-FAM, a Pleiades probe [25] (Table 2). A Pleiades probe is a type of hybridization probe, which allows for real-time DNA detection and subsequent melt curve analysis. The MG23S-R6G probe detects specifically $M$. genitalium, while MG23SFAM discriminates mutants from wild type based on melting curve analysis, i.e., during the melting step of the assay, the probe will be dissociated at a lower temperature from the DNA when containing a mutation at position A2058 or A2059 compared to the wild type. When the melting curve did not allow a clear distinction between A2058G and A2059G, the type of mutation was specified by the use of RTN-qPCR followed by sequencing. 
The $\mathrm{Mg}$ Macrolide ${ }^{\mathbf{R}}$ assay was optimized by testing different primer ratio's (MG23SL1:MG23SE1 of $1: 1 ; 1: 2 ; 1: 4 ; 1: 8$; $1: 16 ; 1: 100)$ and using different qPCR profiles. After optimization, all clinical samples were tested with the $\mathrm{Mg}$ Macrolide $^{\mathbf{R}}$ assay. The assay was performed with $15.0-\mu \mathrm{L}$ PCR mixture using LightCycler® 480 Probes Master (Roche Diagnostics) as master mix. Primers were used in a ratio MG23SL1:MG23SE1 of 1:8. The mix contained $2.0 \mu \mathrm{L}$ of DNA isolates. The qPCR was performed on the LightCycler 480 II (LED) using the following qPCR profile: denaturation at $95{ }^{\circ} \mathrm{C}$ for $10 \mathrm{~min}, 45$ amplification cycles consisting of $95{ }^{\circ} \mathrm{C}$ for $15 \mathrm{~s}$, annealing at $56^{\circ} \mathrm{C}$ for $30 \mathrm{~s}$, and extension at $72{ }^{\circ} \mathrm{C}$ for $15 \mathrm{~s}$. Directly after amplification, a melting step was performed, consisting of $95{ }^{\circ} \mathrm{C}$ for $15 \mathrm{~s}$, $40{ }^{\circ} \mathrm{C}$ for $1 \mathrm{~min}$, and a slow increase in temperature to $80^{\circ} \mathrm{C}$ with the continuous acquisition of fluorescence and finally cooling at $40{ }^{\circ} \mathrm{C}$ for $30 \mathrm{~s}$.

\section{Testing of the specificity of the Mg Macrolide ${ }^{R}$ qPCR}

To determine specificity of the $\mathrm{Mg}$ Macrolide $^{\mathbf{R}}$ qPCR, it was tested on several urogenital pathogens: Acinetobacter baumannii, Acinetobacter calcoaceticus, Candida albicans, Citrobacter freundii, Chlamydia trachomatis, Enterobacter aerogenes, Enterobacter cloacae, Enterococcus faecalis, Enterococcus faecium, Escherichia coli, Klebsiella oxytoca, Klebsiella pneumoniae, Morganella morganii, Neisseria gonorrhoeae, Proteus mirabilis, Proteus vulgaris, Pseudomonas aeruginosa, Serratia liquifaciens, Serratia marcescens, Staphylococcus aureus, Staphylococcus epidermidis, Staphylococcus haemolyticus, Staphylococcus hominis, Stenotrophomonas maltophilia, Streptococcus agalactiae, or Ureaplasma parvum. In addition, our $\mathrm{Mg}$ Macrolide $^{\mathbf{R}}$ qPCR was also tested on an additional 56 urogenital samples that had previously been tested negative for any STD.

\section{Results}

\section{Detection of $M$. genitalium using the $M g$ Macrolide ${ }^{\mathrm{R}}$ qPCR}

M. genitalium was detected in the $\mathrm{Mg}$ Macrolide ${ }^{\mathbf{R}}$ qPCR using the hydrolysis probe MG23S-R6G. Of the 236 sequenced samples, $202(85.6 \%)$ samples were tested positive using the $\mathrm{Mg}$ Macrolide $^{\mathbf{R}}$ qPCR (Table 3). The $\mathrm{Mg}$ MacrolideR qPCR was not able to detect $M$. genitalium in $34 / 236(14.4 \%)$ isolates. The initial Cq-value of these isolates were between 34 and 40 for 5 isolates and all other isolates had initial Cq-values above 40. The assay detected the majority of the sequenced samples that were determined after the standard Mg23S qPCR (165/172, 95.9\%). In addition, more than half of the sequenced samples whose substitutions could be determined only after the RTN-PCR $(37 / 64,57.8 \%)$ were detected by the $\mathrm{Mg}$ Macrolide $^{\mathbf{R}}$ assay as well.

The Mg Macrolide ${ }^{\mathbf{R}}$ qPCR could detect more samples (30/ $23612.7 \%$ ) compared to the standard Mg23S PCR followed by sequencing. 196/236 (83.1\%) samples were tested positive for the $\mathrm{MgPa}$ operon. The $\mathrm{Mg}$ Macrolide ${ }^{\mathbf{R}} \mathrm{qPCR}$ could detect six extra isolates $(6 / 202,3.0 \%)$ compared to the MgPa assay.

\section{Direct detection of macrolide resistance-associated mutations by the $M g$ Macrolide ${ }^{\mathrm{R}}$ assay}

Macrolide resistance-associated mutations in $M$. genitalium were detected by the melt probe MG23S-FAM. Wild type or mutated genes were identified in all 202 samples that were positive for $M$. genitalium using the hydrolysis probe MG23S-R6G. Figure 1 shows representative melting peaks of several samples. The average of the top of the melting peaks $\left(T_{\mathrm{m}}\right)$ of wild types was located at approximately $64{ }^{\circ} \mathrm{C}$, the mutant A2058C was located at $59{ }^{\circ} \mathrm{C}$, the mutant $\mathrm{A} 2058 \mathrm{~T}$ at $55^{\circ} \mathrm{C}$, and the mutant $\mathrm{A} 2058 \mathrm{G}$ and $\mathrm{A} 2059 \mathrm{G}$ at $53{ }^{\circ} \mathrm{C}$. One sample showed a curve in between wild type and the $\mathrm{C}$ mutation but was identified as wild type when analyzing the sequence. The other 201/202 (99.5\%) were concordant with sequencing.

\section{Identification of macrolide resistance-associated mutations}

The sequence of the $23 \mathrm{~S}$ rRNA fragment containing putative resistance mutations of 172/236 (72.9\%) was determined using the amplification product of the standard Mg23S qPCR (Table 3). When the standard method did not give results, RTN-qPCR was used to determine the sequence of the remaining 64/236 (27.1\%) samples. The majority of the samples were wild type $(185 / 236,78.4 \%)$. In 51/236 (21.6\%) samples, different mutations were found. The mutation $\mathrm{A} 2058 \mathrm{G}$ was found most frequently $(22 / 51,43.1 \%)$, followed by A2059G $(17 / 51,33.3 \%)$, A2058T (8/51, 15.7\%), A2058C (3/62, 5.9\%), and A2059C (1/51, 2.0\%).

\section{Specificity of the Mg Macrolide ${ }^{\mathrm{R}}$ qPCR}

None of the other tested urogenitalmicro-organisms then $M$. genitalium were tested positive in the $M$. genitalium $\mathrm{Mg}$ Macrolide $^{\mathbf{R}}$ qPCR, indicating a high specificity. In addition, all 56 urine samples that were originally negative tested for any STD were tested negative using the $\mathbf{M g}$ Macrolide $^{\mathbf{R}}$ qPCR as well. 
Table 3 Comparison between the results of the sequenced samples after the standard Mg23S qPCR and the $\mathrm{Mg}$ Macrolide ${ }^{\mathbf{R}} \mathrm{qPCR}$

\begin{tabular}{llccr}
\hline & $\begin{array}{l}\text { Sequencing after Mg23S } \\
\text { qPCR + RTN-qPCR }\end{array}$ & $\begin{array}{l}\text { Sequencing after } \\
\text { Mg23S qPCR }\end{array}$ & $\begin{array}{l}\text { Mg Macrolide } \\
\text { qPCR }\end{array}$ & Difference \\
\hline WT & 185 & $138(75 \%)$ & $159(86 \%)$ & $21(11 \%)$ \\
Mutants & 51 & $34(67 \%)$ & $43(84 \%)$ & $9(18 \%)$ \\
A2058C & 3 & $2(67 \%)$ & $3(100 \%)$ & $1(33 \%)$ \\
A2058G & 22 & $15(68 \%)$ & $18(82 \%)$ & $3(14 \%)$ \\
A2058T & 8 & $7(88 \%)$ & $8(100 \%)$ & $1(13 \%)$ \\
A2059C & 1 & $0(0 \%)$ & $0(0 \%)$ & $0(0 \%)$ \\
A2059G & 17 & $10(59 \%)$ & $14(82 \%)$ & $4(24 \%)$ \\
Total & 236 & $172(73 \%)$ & $202(86 \%)$ & $30(13 \%)$ \\
\hline
\end{tabular}

\section{Discussion}

Patients suspected for infection with M. genitalium are often treated empirically with azithromycin in the Western world but, unfortunately, empirical treatment is often failing because azithromycin resistance is increasing and can be as high as 50\% [28]. Diagnostic tests to detect azithromycin resistant-associated genes have recently been developed but are not commonly used in routine diagnostics as they tend to be quite laborious and time consuming. In the present paper, a diagnostic test is described that not only detects the presence of $M$. genitalium, but also detects all macrolide resistanceassociated mutations at position A2058 and A2059 in 23S rRNA gene in $M$. genitalium.
The newly developed Mg Macrolide ${ }^{\mathbf{R}}$ qPCR is more sensitive compared to the routine diagnostic PCR based on the $\mathrm{MgPa}$ operon, since six extra isolates $(6 / 202,3.0 \%)$ were detected.

In contrast to most of the studies, in this study, the focus was exclusively on samples derived from general practitioners. Hence, the prevalence of mutations might be slightly different compared to other studies that mainly focus on highrisk patients. Interestingly, we found two third of the samples derived from women. In this study, no significant difference between the prevalence of mutations were found between women and men infected by M. genitalium (data not shown). However, since this study only used a small number of patients' samples, it would be of interest to further investigate the prevalence of resistance in the general population.

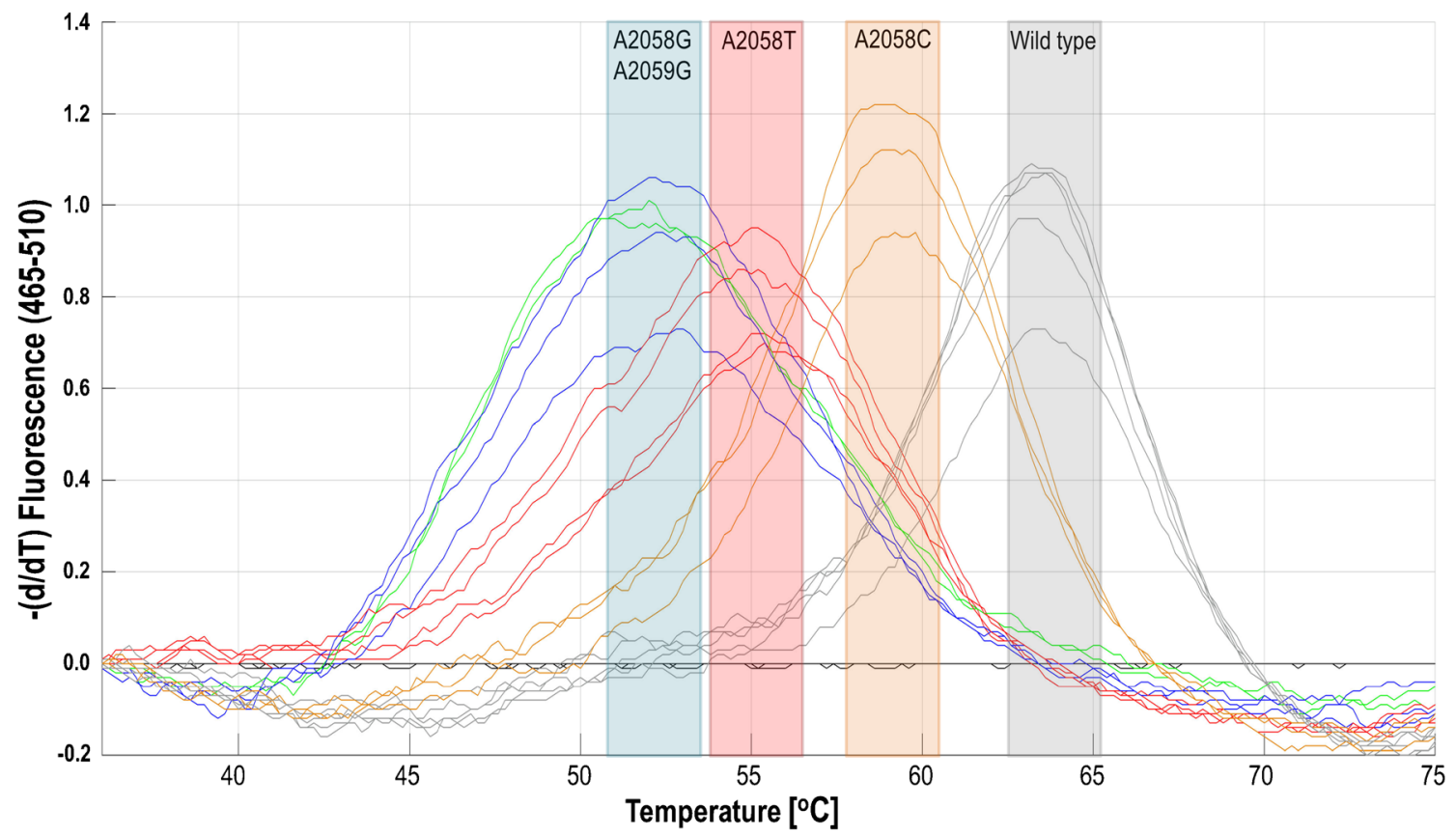

Fig. 1 Typical example of melt peak analysis using the $M g$ Macrolide ${ }^{R}$ qPCR for a set of seventeen clinical samples. Wild type strains are in grey and have a melt peak at $\sim 64^{\circ} \mathrm{C}, \mathrm{A} 2058 \mathrm{C}$ in orange at $\sim 59^{\circ} \mathrm{C}, \mathrm{A} 2058 \mathrm{~T}$ in red at $\sim 55^{\circ} \mathrm{C}, \mathrm{A} 2058 \mathrm{G}$ in blue, and $\mathrm{A} 2059 \mathrm{G}$ in green at $53^{\circ} \mathrm{C}$. No DNA controls are in black. Boxes indicate the location of melt peak bins.
Controls and clinical isolates were analyzed in the same qPCR run. Figure constructed from the original IXO-file output of the real-time PCR LightCycler® 480 with the help of M. Thomann, BSc (Roche Diagnostics International AG, Switzerland) 
Initially, the $\mathrm{MgPa}$ operon was thought to be a perfect target for the detection of $M$. genitalium, since the operon contains repetitive elements termed MgPars. Targeting these multi-copy regions increases the sensitivity of the qPCR. However, the repetitive regions contain extensive variation, while the non-repeat regions contain low-level variation [29]. Detecting all $M$. genitalium strains using these multi-copy regions is, therefore, almost impossible. Although the $23 \mathrm{~S}$ rRNA is a single-copy gene, this gene is very suitable for detection since the $23 \mathrm{~S}$ rRNA is highly conserved. This might explain the difference in sensitivity of the $\mathrm{MgPa}$ assay and $\mathrm{Mg}$ Macrolide ${ }^{\mathbf{R}}$ assay. Using RNA as input obviously increases the sensitivity when compared to DNA as used in our RTN-qPCR sequencing method and is employed by Aptima PCRs [30, 31].

The $\mathrm{Mg}$ Macrolide ${ }^{\mathbf{R}}$ qPCR was also more sensitive compared to the standard Mg23S qPCR. This can be explained by the difference in the length of the amplification product: the amplicon of the Mg23S qPCR is $282 \mathrm{bp}$, while the amplicon of the $\mathrm{Mg}$ Macrolide ${ }^{\mathbf{R}}$ qPCR is $111 \mathrm{bp}$. Therefore, the $\mathrm{Mg}$ Macrolide $^{\mathbf{R}}$ qPCR might be more efficient.

The Mg Macrolide ${ }^{\mathbf{R}}$ qPCR is specific in detecting mutations and a clear distinction can be made between the melting peaks of wild type and mutants. With exception of A2058G and $\mathrm{A} 2059 \mathrm{G}$, there is also a clear difference between the mutants. While the average of the melting peaks was stable (not shown), this is highly dependent on the PCR setup. Therefore it is necessary to always include the relevant controls.

Mutations detected by this qPCR were fully consistent for 201/202 (99.5\%) samples with sequencing data. One sample showed a curve in between wild type and the C-mutation but was identified as wild type when analyzing the sequence. Possibly, the sample contained a mixed population of wildtype and C-mutants, and direct sequencing of PCR products identified only the major population and the smaller population of $\mathrm{C}$ mutants was only detected by our qPCR. The isolate would be determined as non-wild type, and thus treatment with azithromycin would not be recommended, while in the sequence-based analysis, it would have been typed as wildtype and hence azithromycin treatment would have been recommended. As this might be an isolate containing both wild type and mutant $M$. genitalium, so if one is optimistic, one might even claim a $100 \%$ specificity.

The $\mathrm{Mg}$ Macrolide ${ }^{\mathbf{R}}$ qPCR was not able to detect $M$. genitalium in 34/236 (14.4\%) isolates. The Cq-value of these isolates was determined and only 5/34 had a lower Cq-value between 34 and 40. All the other isolates had Cq-values above 40 or could not be determined (data not shown). The inability to detect $M$. genitalium in these isolates can be explained by DNA degradation, since the Mg Macrolide ${ }^{\mathbf{R}}$ qPCR was performed more than a year later after sample collection. The $\mathrm{Mg}$ Macrolide $^{\mathbf{R}}$ qPCR will likely detect more samples when the test is performed directly after sample collection. Another explanation for not detecting $M$. genitalium in all samples is the use of the asymmetrical assay, since best results with the $\mathrm{Mg}$ Macrolide $^{\mathbf{R}}$ assay were found when the primer ratio MG23SL1:MG23SE1 of 1:8 was used. This results in less competition between the MG23S-FAM probe and the complementary DNA strain, and a higher fluorescence signal. This might have an effect on the sensitivity of the assay since amplification will not be exponential, but more linear.

Recently, several qPCR-based methods to detect macrolide resistance in $M$. genitalium have been described. Most of them have some disadvantages when compared to our qPCR, as our assay can detect $M$. genitalium and at the same time, macrolide resistance-associated mutations. Other qPCRs like the monoplex PCR [21] and the FRET qPCR need more reactions [19]. The $\mathrm{Mg}$ Macrolide ${ }^{\mathbf{R}}$ qPCR is more sensitive compared to the standard $M$. genitalium detection qPCR, while the FRET qPCR of Touati et al. was less sensitive compared to their standard M. genitalium detection qPCR [19]. The Mg Macrolide ${ }^{\mathbf{R}}$ qPCR might also be more sensitive than the monoplex PCR of Wold et al. since they only used clinical samples with a Cq-value of < 32 [21]. Preselection of samples with a relatively high bacterial load suggests that the sensitivity of this assay may limit its utility in clinical routine.

Another advantage is the ability to detect different mutations with only one probe. qPCRs with hydrolysis probes need at least six different probes to detect wild type and all five mutants described so far (A2058C, A2058G, A2058T, A2059C, and A2059G). qPCRs that detect only wild type and the most common mutations A2058G and A2059G, such as the hydrolysis probe assay by Kristiansen et al, [17], and depending on the local prevalence, will possibly miss a significant part of the resistant strains [32]. Lastly, the analysis of melting curves is relatively easy compared to the hydrolysis probe assay by Kristiansen et al [17].

Recently, the multiplex qPCR assay developed by SpeeDx has shown to be sensitive and specific for the detection of $M$. genitalium and macrolide resistance-associated mutations [22-24]. Because of the promising results of the $\mathrm{Mg}$ Macrolide ${ }^{\mathrm{R}} \mathrm{qPCR}$, it would be of interest to compare the assays for ease of use and performance in a routine setting. Furthermore, it would be interesting to also include an RNA-based qPCR method like Aptima, as is expected that this would result in a higher sensitivity [30, 31].

In this report, a FRET-probe-based $\mathrm{Mg}$ Macrolide ${ }^{\mathbf{R}}$ qPCR was described that has shown to be both sensitive and specific for detecting $M$. genitalium and macrolide resistanceassociated mutations. The $\mathrm{Mg}$ Macrolide ${ }^{\mathbf{R}}$ qPCR can be used in routine diagnostic but has also potential to distinguish between most of the mutations. Therefore, it might be of interest to use this assay in research settings. The $\mathrm{Mg}$ Macrolide $^{\mathbf{R}}$ assay is planned to be used in a large-scale study to investigate superiority to the MgPa assay, the multiplex qPCR of SpeeDx and an RNA-based qPCR; and to investigate the prevalence of resistant $M$. genitalium in a large study group. 
Acknowledgements We would like to thank Dr. E.C.H. Boel and W. S. Voskuil of the department of Medical Microbiology, UMC Utrecht, the Netherlands, B. Slotboom, Dr. N. M. van Maarseveen and Dr. T. van Zwet of the Laboratory for Medical Microbiology and Immunology Rijnstate, the Netherlands, Dr. H. Berkhout and Dr. F. Hagen of Laboratory for Medical Microbiology and Infectious diseases CWZ, the Netherlands, and Dr. J.H.B. van de Bovenkamp and Dr. L. van Dommelen of Laboratory of Medical Microbiology PAMM, the Netherlands for helpful discussions and assistance with collection of $M$. genitalium samples.

\section{Compliance with ethical standards}

Conflict of interest J.F.B., S.v.M., T.T.S. and J.G.K have no competing interests to declare. Y.B. is an employee of ELITechGroup Inc. USA. W.M. is an employee of ELITechGroup Inc. USA and works in emergency medicine at a local non-profit hospital.

Ethical approval All involved hospitals have an opt-out-system regarding research on archival patient material, and only material from patients that did not opt-out has been included in this study. The local ethics boards of all involved hospitals allow the use of the archival waste materials, provided that none of the involved researchers has access to any personal patient data.

Informed consent As this study only used archival waste material, the local ethics committee approved this study without written informed consent.

Open Access This article is distributed under the terms of the Creative Commons Attribution 4.0 International License (http:// creativecommons.org/licenses/by/4.0/), which permits unrestricted use, distribution, and reproduction in any medium, provided you give appropriate credit to the original author(s) and the source, provide a link to the Creative Commons license, and indicate if changes were made.

\section{References}

1. Taylor-Robinson D, Jensen JS (2011) Mycoplasma genitalium: from Chrysalis to multicolored butterfly. Clin Microbiol Rev 24(3):498-514

2. Pond MJ, Nori AV, Witney AA, Lopeman RC, Butcher PD, Sadiq ST (2014) High prevalence of antibiotic-resistant Mycoplasma genitalium in nongonococcal urethritis: the need for routine testing and the inadequacy of current treatment options. Clin Infect Dis 58(5):631-637

3. Gottesman T, Yossepowitch O, Samra Z, Rosenberg S, Dan M (2017) Prevalence of Mycoplasma genitalium in men with urethritis and in high risk asymptomatic males in Tel Aviv: a prospective study. Int J STD AIDS 28(2):127-132

4. Haggerty CL (2008) Evidence for a role of Mycoplasma genitalium in pelvic inflammatory disease. Curr Opin Infect Dis 21(1):65-69

5. Lis R, Rowhani-Rahbar A, Manhart LE (2015) Mycoplasma genitalium infection and female reproductive tract disease: a meta-analysis. Clin Infect Dis 61(3):418-426

6. Andersen B, Sokolowski I, Ostergaard L, Kjolseth Moller J, Olesen F, Jensen JS (2007) Mycoplasma genitalium: prevalence and behavioural risk factors in the general population. Sex Transm Infect 83(3):237-241

7. Sonnenberg P, Ison CA, Clifton S, Field N, Tanton C, Soldan K, Beddows S, Alexander S, Khanom R, Saunders P, Copas AJ, Wellings K, Mercer CH, Johnson AM (2015) Epidemiology of Mycoplasma genitalium in British men and women aged 16-44 years: evidence from the third National Survey of Sexual Attitudes and Lifestyles (Natsal-3). Int J Epidemiol 44(6):19821994

8. Jensen JS, Blom J, Lind K (1994) Intracellular location of Mycoplasma genitalium in cultured Vero cells as demonstrated by electron microscopy. Int J Exp Pathol 75(2):91-98

9. Jensen JS, Uldum SA, Sondergard-Andersen J, Vuust J, Lind K (1991) Polymerase chain reaction for detection of Mycoplasma genitalium in clinical samples. J Clin Microbiol 29(1):46-50

10. Eastick K, Leeming JP, Caul EO, Horner PJ, Millar MR (2003) A novel polymerase chain reaction assay to detect Mycoplasma genitalium. Mol Pathol 56(1):25-28

11. Taylor-Robinson D, Horner PJ (2001) The role of Mycoplasma genitalium in non-gonococcal urethritis. Sex Transm Infect 77(4): 229-231

12. Horner P, Blee K, Adams E (2014) Time to manage Mycoplasma genitalium as an STI: but not with azithromycin $1 \mathrm{~g}$ ! Curr Opin Infect Dis 27(1):68-74

13. Ito S, Shimada Y, Yamaguchi Y, Yasuda M, Yokoi S, Ito S, Nakano M, Ishiko H, Deguchi T (2011) Selection of Mycoplasma genitalium strains harbouring macrolide resistance-associated 23S rRNA mutations by treatment with a single $1 \mathrm{~g}$ dose of azithromycin. Sex Transm Infect 87(5):412-414

14. Jensen JS, Cusini M, Gomberg M, Moi H (2016) 2016 European guideline on Mycoplasma genitalium infections. J Eur Acad Dermatol Venereol 30(10):1650-1656

15. Lau A, Bradshaw CS, Lewis D, Fairley CK, Chen MY, Kong FY, Hocking JS (2015) The efficacy of azithromycin for the treatment of genital Mycoplasma genitalium: a systematic review and metaanalysis. Clin Infect Dis 61(9):1389-1399

16. Jensen JS, Bradshaw CS, Tabrizi SN, Fairley CK, Hamasuna R (2008) Azithromycin treatment failure in Mycoplasma genitaliumpositive patients with nongonococcal urethritis is associated with induced macrolide resistance. Clin Infect Dis 47(12):1546-1553

17. Kristiansen GQ, Lisby JG, Schonning K (2016) A 5' -nuclease genotyping assay for identification of macrolide-resistant Mycoplasma genitalium in clinical specimens. J Clin Microbiol 54(6):1593-1597

18. Twin J, Jensen JS, Bradshaw CS, Garland SM, Fairley CK, Min LY, Tabrizi SN (2012) Transmission and selection of macrolide resistant Mycoplasma genitalium infections detected by rapid high resolution melt analysis. PLoS One 7(4):e35593

19. Touati A, Peuchant O, Jensen JS, Bebear C, Pereyre S (2014) Direct detection of macrolide resistance in Mycoplasma genitalium isolates from clinical specimens from France by use of real-time PCR and melting curve analysis. J Clin Microbiol 52(5):1549-1555

20. Gossé M, Lysvand H, Pukstad B, Nordbø SA (2016) A novel SimpleProbe PCR assay for detection of mutations in the $23 \mathrm{~S}$ rRNA gene associated with macrolide resistance in Mycoplasma genitalium in clinical samples. J Clin Microbiol 54(10):2563-2567

21. Wold C, Sorthe J, Hartgill U, Olsen AO, Moghaddam A, Reinton N (2015) Identification of macrolide-resistant Mycoplasma genitalium using real-time PCR. J Eur Acad Dermatol Venereol 29(8):1616-1620

22. Tan LY, Walker SM, Lonergan T, Lima NE, Todd AV, Mokany E (2017) Superior multiplexing capacity of PlexPrimers enables sensitive and specific detection of SNPs and clustered mutations in qPCR. PLoS One 12(1):e0170087

23. Tabrizi SN, Tan LY, Walker S, Twin J, Poljak M, Bradshaw CS, Fairley CK, Bissessor M, Mokany E, Todd AV (2016) Multiplex assay for simultaneous detection of Mycoplasma genitalium and macrolide resistance using PlexZyme and PlexPrime technology. PLoS One 11(6):e0156740

24. Tabrizi SN, Su J, Bradshaw CS, Fairley CK, Walker S, Tan LY, Mokany E, Garland SM (2017) Prospective evaluation of ResistancePlus MG, a new multiplex quantitative PCR assay for 
detection of Mycoplasma genitalium and macrolide resistance. J Clin Microbiol 55(6):1915-1919

25. Lukhtanov EA, Lokhov SG, Gorn VV, Podyminogin MA, Mahoney W (2007) Novel DNA probes with low background and high hybridization-triggered fluorescence. Nucleic Acids Res 35(5): 30

26. Nijhuis RH, Severs TT, Van der Vegt DS, Van Zwet AA, Kusters JG (2015) High levels of macrolide resistance-associated mutations in Mycoplasma genitalium warrant antibiotic susceptibility-guided treatment. J Antimicrob Chemother 70(9):2515-2518

27. Jensen JS, Bjornelius E, Dohn B, Lidbrink P (2004) Use of TaqMan 5 ' nuclease real-time PCR for quantitative detection of Mycoplasma genitalium DNA in males with and without urethritis who were attendees at a sexually transmitted disease clinic. J Clin Microbiol 42(2):683-692

28. Getman D, Jiang A, O'Donnell M, Cohen S (2016) Mycoplasma genitalium prevalence, coinfection, and macrolide antibiotic resistance frequency in a multicenter clinical study cohort in the United States. J Clin Microbiol 54(9):2278-2283

29. Ma L, Jensen JS, Mancuso M, Hamasuna R, Jia Q, McGowin CL, Martin DH (2010) Genetic variation in the complete MgPa operon and its repetitive chromosomal elements in clinical strains of Mycoplasma genitalium. PLoS One 5(12):e15660

30. Unemo M, Salado-Rasmussen K, Hansen M, Olsen AO, Falk M, Golparian D, Aasterod M, Ringlander J, Nilsson CS, Sundqvist M, Schonning K, Moi H, Westh H, Jensen JS (2018) Clinical and analytical evaluation of the new Aptima Mycoplasma genitalium assay, with data on M. genitalium prevalence and antimicrobial resistance in M. genitalium in Denmark, Norway and Sweden in 2016. Clin Microbiol Infect 24(5):533-539

31. Le Roy C, Pereyre S, Henin N, Bebear C (2017) French prospective clinical evaluation of the Aptima Mycoplasma genitalium CE-IVD assay and macrolide resistance detection using three distinct assays. J Clin Microbiol 55(11):3194-3200

32. Braam JF, Slotboom B, Van Marm S, Severs TT, Van Maarseveen NM, Van Zwet T, Boel ECH, Berkhout H, Hagen F, Van De Bovenkamp JHB, Van Dommelen L, Kusters JG (2017) High prevalence of the A2058T macrolide resistance-associated mutation in Mycoplasma genitalium strains from the Netherlands. J Antimicrob Chemother 72(5):1529-1530 